\title{
EGFR inhibitor C225 Increases the Radio-Sensitivity of Human Breast Cancer Cells
}

\author{
Zhifeng Yao ${ }^{1,2}$, Peng Peng ${ }^{3}$, Danghui Xu ${ }^{4}$, Xuejun Zhou ${ }^{5}$, Zhiyao Pan ${ }^{6}$, Zhanfeng \\ $\mathrm{Li}^{7}$, Jianxin Yao ${ }^{7}$, Jinfei Chen ${ }^{1,8 *}$
}

\begin{abstract}
Objective: This study was undertaken to investigate the effect of C225 on the radio-sensitivity of MDA-MB-231 cells line and to disclosure underlying mechanism. Methods: CCK8 assay was used to measure the proliferation inhibition of C225 on MDA-MB-231 cells. The combined effects of C225 plus radiation on the proliferation of MDA-MB-231 cells were also evaluated by CCK-8 assay. The clonogenic assay was performed to evaluate the cell surviving fractions and to determine the radio-sensitizing effect of $\mathrm{C} 225$ on MDA-MB-231 cells. The apoptosis and cell cycle distribution were analyzed by flow cytometry. Western blot analysis was used to detect the expression of p-EGFR, p-Akt, p-P38, and caspase-3. Results: C225 had an inhibiting effect on the proliferation of cells in a concentration-dependent manner. The cloning formation capacity was decreased in C225 plus radiation group. C225 increased radio-sensitivity of cells and led to cell cycle arrest in G0/G1 phase markedly. Cells treated with $\mathrm{C} 225$ and radiation predominantly exhibited G0/G1 phase arrest and significant decreased in the fraction of cells in the S phase. Moreover, C225 and radiation significantly increased the apoptosis rate of cells. Decreased cell proliferation was further supported by the down-regulation of p-EGFR and its downstream singling pathway proteins such as p-Akt and p-P38. The up-regulation of the Caspase-3 expression in $\mathrm{C} 225$ plus radiation group revealed that $\mathrm{C} 225$ could increase radiation-inducing cell apoptosis. Conclusion: $\mathrm{C} 225$ could increase the radio-sensitivity of cells, which may be due to the anti-proliferative synergistic effect between $\mathrm{C} 225$ and radiation as well as the down-regulation of the PI3K/Akt signaling pathway.
\end{abstract}

Keywords: Cetuximab- epidermal growth factor receptor- radio-sensitization-PI3K/Akt signaling pathway

Asian Pac J Cancer Prev, 20 (1), 311-319

\section{Introduction}

Breast cancer is the second most frequent cancer among women, with an estimation of 1.67 million new cases occurring in 2012, according to IARC (Guillermo et al., 2018). It is the leading cause of cancer-related death among the female population worldwide (Jemal et al., 2011). Triple negative breast cancer (TNBC) is a subtype of breast cancer which is estrogen receptor (ER) negative, progesterone receptor (PR) negative, and human epidermal growth factor receptor-2 (HER-2) negative (Yao et al., 2014; Kaya et al., 2018). TNBC accounts for approximately $15-20 \%$ of breast cancer cases and it a distinct pathological subtype of breast cancer with specific clinical and pathological characteristics (Mouh et al., 2016). Because of the negative expression of ER,
PR and lack of over-expression of HER-2, TNBC doesn't respond to both endocrine therapy and targeted therapy of trastuzumab. The high risk of invasiveness and metastasis leads to the highest degree of malignancy and the worst prognosis in various subtypes of breast cancer (Williams and Lin, 2013; Oostra and Macrae, 2014).

Growth factors control cellular proliferation and differentiation. They are important for the initiation and maintenance of neo-plastic transformation. Transforming growth factor (TGF) and epidermal growth factor (EGF) and its specific receptors, the epidermal growth factor receptor (EGFR), have been implicated in the progression of the majority of human epithelial cancers (Krause et al., 2007). EGFR -mediated activation signals are not only critical for cell proliferation, but also contribute to other processes that are crucial for cancer progression,

${ }^{1}$ Department of Oncology, Nanjing First Hospital, Nanjing Medical University, ${ }^{2}$ Department of Radiation Oncology, The Second Affiliated Hospital of Nanjing Medical University, ${ }^{3}$ Department of Nursing, Nanjing Health College of Jiangsu Union Technical Institute, ${ }^{4}$ Department of Medical Imaging, Jiangsu Provincial Hospital of Traditional Chinese Medicine, ${ }^{7}$ Department of Medical Imaging, Nanjing Health College of Jiangsu Union Technical Institute, ${ }^{8}$ Department of Oncology, The Affiliated Taikang Xianlin Drum Tower Hospital of Nanjing University Medical School, Nanjing, ${ }^{5}$ Department of Medical Imaging, The Affiliated Hospital of Nantong University, Nantong, Jiangsu Province, ${ }^{6}$ Department of Basic Medical Sciences, Zhejiang University, Hangzhou, Zhejiang Province, China. *For Correspondence: jinfeichen19650922@163.com.Zhi-feng Yao, and Peng Peng have equal contribution in this study. 
including angiogenesis, metastatic spread, and inhibition of apoptosis (Dittmann et al., 2005; Liu et al., 2007). The high expression of EGFR is also associated with resistance to ionizing radiation, as determined in several preclinical models. EGFR activation may prevent radiation-induced apoptosis in cancer cells. This may be clinically relevant because it could represent a mechanism via which cancer cells escape radiation-induced cell death. The expression of EGFR is positive in about $50-60 \%$ TNBC patients, so the effect of postoperative radiotherapy is even worse than other types of breast cancer with negative expression of EGFR.

Cetuximab (C225), a monoclonal antibody (mAb) against the extracellular domain of EGFR, can block the activation of EGFR as the result of the competitive conjugation to the endogenous ligand of EGFR, which has been clinically used for the therapy of human head and neck cancers and colon cancers (Italiano et al., 2006; Sok et al., 2006; Zhou et al., 2006; Liang ZG et al., 2018; Takada et al., 2018). Although there is no research on the mechanism of radiation sensitizing effect of $\mathrm{C} 225$ on the TNBC cells, there are many studies on the relationship between $\mathrm{C} 225$ and the radiation sensitivity of the head and neck squamous cell carcinoma and lung cancer (Diaz et al., 2009; Rades et al., 2009).

In the present study, we investigated the radio-sensitivity of C225 on TNBC MDA-MB-231 cells and disclosed the underlying mechanism by detecting cell proliferation, cell cycle, and apoptosis in MDA-MB-231 cells. EGFR and its downstream PI3K/Akt signaling pathway as well as apoptosis-associated genes play an important role in radiation resistance of tumors (Gupta et al., 2001), so this investigation also discussed whether $\mathrm{C} 225$ enhance the radio-sensitivity of MDA-MB-231 cells by blocking the PI3K/Akt signaling pathway. We also explored the apoptosis regulatory mechanism of $\mathrm{C} 225$ combined with radiation on MDA-MB-231 cells in order to achieve more in-depth understanding of radio-sensitization of C225 to TNBC and provide the experimental evidence for the radiation sensitivity of TNBC.

\section{Materials and Methods}

\section{Cell line and cell culture}

Human breast cancer (MDA-MB-231) cells were provided by the Type Culture Collection of Chinese Academy of Sciences, Shanghai, China. These cells were routinely cultured in Dulbecco's modified Eagle' medium (DMEM) supplemented with 10\% heat-inactivated fetal bovine serum (FBS), $100 \mathrm{U} / \mathrm{ml}$ penicillin, and $100 \mu \mathrm{g} / \mathrm{ml}$ streptomycin in a humidified $5 \% \mathrm{CO}_{2}$ atmosphere containing at $37^{\circ} \mathrm{C}$.

\section{Reagents and Equipment}

High glucose medium DMEM, 0.25\% trypsin, PBS, penicillin-streptomycin solution, and Giemsa solution were obtained from Gibco Company. Fetal calf serum (FCS) was purchased from Sijiqing Company, Hangzhou. DMSO and Annexin V-FITC /PI cell apoptosis kit were purchased from Kaiji Company, Nanjing. Mouse monoclonal antibody against p-EGFR, p-Akt, and
p-P38, mouse monoclonal antibody against $\beta$-actin, and horseradish peroxidase (HRP)-conjugated anti-mouse antibody were purchased from Santa Cruz Company. C225 $(2 \mathrm{mg} / \mathrm{ml})$ was provided by the German Merck Company, Flow cytometry (FACS Calibur, Beckman Coulter Company). Linear accelerate (ELEKTA Company).

\section{Cell radiation}

The cells were divided into two groups: radiation group and $\mathrm{C} 225$ plus radiation group. The radiation rate was 300 $\mathrm{cGy} / \mathrm{min}$. All radiation was carried out using $6 \mathrm{MV}$ X-ray linear accelerator with $100 \mathrm{~cm}$ source skin distance-SSDand $15 \mathrm{~cm} \times 15 \mathrm{~cm}$ exposure field.

The inhibitory effect of different concentrations of $C 225$ on the proliferation of $M D A-M B-231$ cells

The cells were divided into the experimental group and the control group. After cells were adherent for 24 $\mathrm{h}$, cells medium in the experimental group were replaced with $200 \mu \mathrm{l}$ medium containing different concentrations of C225 $(1,5,25,125$, and $625 \mathrm{nmol} / \mathrm{l})$, while cells in the control group were only treated with the same medium. They were cultured for $48 \mathrm{~h}$. Then, the culture medium was discarded. Next, $100 \mu \mathrm{l}$ culture medium and $10 \mu \mathrm{l}$ of CCK8 reagent were added to each hole. After that, the cells in the 96 holes plate were incubated for $4 \mathrm{~h}$. The optical density (OD) value of each hole at the wavelength of $450 \mathrm{~nm}$ was measured by an enzyme-labeled meter. The drug concentration was repeated three times, and the cell proliferation inhibition rate was calculated by the following formula:

Cell proliferation inhibition rate $=(1-$ OD value from experimental group/OD value from control group) $\times 100 \%$.

The half inhibitory concentration $(50 \%$ inhibition concentration or $\mathrm{IC}_{50}$ ) was calculated according to the inhibitory rate of cell proliferation and $\mathrm{C} 225$ concentration, and $\mathrm{IC}_{50}$ of C225 was $(151+2.98) \mathrm{nmol} / \mathrm{l}$. Next, $20 \% \mathrm{IC}_{50}$ $(30 \mathrm{nmol} / \mathrm{l})$ was taken as the concentration in the follow-up experiment of radiation sensitizing effect. The experiment was repeated three times.

The inhibitory effect of $C 225$ combined with radiation on the proliferation of $M D A-M B-231$ cells

MDA-MB-231 cells were divided into two groups: radiation group and $\mathrm{C} 225$ plus radiation group. The exposure doses of the radiation group were $0,2,4,6$, and $8 \mathrm{~Gy}$. C225 (30 nmol/1) was acted on cells before exposing to the above mentioned doses in the $\mathrm{C} 225$ plus radiation group. Then, CCK-8 assay was tested on cells treated for $48 \mathrm{~h}$ (the same method was used). There duplicate holes were set at each dose point. The cell proliferation inhibition rate was calculated according to the above mentioned formula. The combined effect was calculated according to the following formula:

$$
(\mathrm{Q}=\mathrm{E}(\mathrm{A}+\mathrm{B}) /[\mathrm{EA}+(1-\mathrm{EA}) \times \mathrm{EB}]
$$

$\mathrm{E}(\mathrm{A}+\mathrm{B})$ represented the inhibitory rate of $\mathrm{C} 225$ plus radiation group and $\mathrm{EA}$ and $\mathrm{EB}$ represented the inhibitory rate of $\mathrm{C} 225$ group and radiation group, respectively. 
$\mathrm{Q}(0.85-1.15), \mathrm{Q}>1.15$, or $\mathrm{Q}<0.85$ indicated that the interactions between $\mathrm{C} 225$ and radiation were additive, synergistic, or antagonistic, respectively.

\section{Cell clonogenic survival assay}

Logarithmically growing cells were re-suspended and plated in wells of 6-well dishes with a culture containing medium alone or medium supplemented with C225 (30 $\mathrm{nmol} / \mathrm{l})$ at different number of cells $(200,500,1,000$, 2,000 , and 4,000) in accordance with laddered doses of radiation $(0,2,4$, and $6 \mathrm{~Gy})$. After treating with $\mathrm{C} 225$ for $24 \mathrm{~h}, \mathrm{C} 225$ was removed and the cells were radiated and incubated in a continually humidified atmosphere. After 14 days, when cell colonies were formed, the visible colonies with more than 50 cells were counted. Plating efficiency (PE) was calculated relative to the control group (0 Gy), and survival fraction (SF) of each group was determined using the following equation:

$$
\mathrm{SF}=\text { colony number/ }(\text { plating cell number } \times \mathrm{PE})
$$

The dose-survival curve was fitted by the single-hit multi-target statistical model $\mathrm{SF}=1-\left(1-\mathrm{e}^{-\mathrm{D} / \mathrm{D} 0}\right)^{\mathrm{N}}$ using SPSS (version 17) to calculate several survival parameters including $\mathrm{SF}_{2}$ (surviving fraction of $2 \mathrm{~Gy}$ ), $\mathrm{D}_{0}$ (mean lethal dose or final slope), and $\mathrm{D}_{\text {q }}$ (quasi-threshold dose). Three parallel samples were set at each radiation dosage.

\section{Analysis of cell apoptosis by flow cytometry}

The apoptosis was examined according to the procedure described in the instruction for the use of Annexin V-FITC/PI kit. Briefly, cells in the exponential growth phase were seeded in a 6-well culture plate at the concentration of $5 \times 10^{5}$ cells $/ \mathrm{ml}$, added with $2 \mathrm{ml}$ medium/well and cultured overnight. The cells were divided into two groups as follows: 1) radiation group: cells were exposed to certain doses of $6 \mathrm{MV}$ X-ray (0, $2,4,6$, and $8 \mathrm{~Gy})$; 2) radiation plus $\mathrm{C} 225$ group: cells were exposed to $30 \mathrm{nmol} / 1$ of $\mathrm{C} 225$ before exposing to the corresponding doses. Three parallel wells were prepared for each group. Then, the treated cells were rinsed twice in PBS and trypsinized for 1 min to obtain a single cell suspension. After that, the trypsinization was stopped with medium. The cells were rinsed twice in pre-cooled PBS, added with $5 \mu \mathrm{l}$ of Annexin V and $5 \mu \mathrm{l}$ of PI for staining for $30 \mathrm{~min}$ at the room temperature keeping away from light. The cells were subject to flow cytometry for apoptosis detection (Excitation wavelength: $488 \mathrm{~nm}$ and emission wavelength: $670 \mathrm{~nm}$ ). The experiment was repeated three times.

\section{Analysis of cell cycle by flow cytometry}

The cells in exponential growth phase were seeded in a 6 -well culture plate at $5 \times 10^{5}$ cells/well, supplemented with $2 \mathrm{ml} \mathrm{medium/well,} \mathrm{and} \mathrm{cultured} \mathrm{overnight.} \mathrm{The}$ cells were divided into four groups as follows: 1) control group: no treatment; 2) C225 (30 nmol/1) group; 3) 8 Gy radiation group; 4) 8 Gy radiation plus C225 (30 nmol/1) group: cells were exposed to C225 (30 nmol/1) before radiation. These cells were simultaneously dealt in DMEM medium supplemented with $1 \%$ fetal calf serum for $24 \mathrm{~h}$ and then the cells were exposed to $0.1 \%$ DMSO or $30 \mathrm{nmol} / 1 \mathrm{C} 225$ or $8 \mathrm{~Gy}$ radiation or $8 \mathrm{~Gy}$ radiation plus $30 \mathrm{nmol} / 1 \mathrm{C} 225$, and then continued to incubate in DMEM medium supplemented with $10 \%$ fetal calf serum for $72 \mathrm{~h}$. Then, the cells were harvested and washed by cold PBS twice and fixed in ethanol $70 \%\left(4^{\circ} \mathrm{C}\right)$, then stained in PI in darkness. Distribution of cell cycle was analyzed by flow cytometry. The experiment was repeated three times.

\section{Western blot analysis}

MDA-MB-231 cells were exposed to $30 \mathrm{nmol} / \mathrm{l} \mathrm{C} 225$ for $24 \mathrm{~h}$. Then, cells were harvested and washed with ice-cold PBS three times. Finally, they were centrifuged and treated with cell lysate. Total protein concentration was determined by BCA method, using bovine serum albumin (BSA) as standard. Twenty micrograms $(\mu \mathrm{g})$ of total cell lysate were boiled for $5 \mathrm{~min}$. Equal amounts of protein in the cell extracts were fractionated by $10 \%$ SDS-PAGE denaturing gels, then electro-transferred to the PVDF membranes. The transfer of proteins was confirmed by Ponceau-S staining. The membranes were blocked in $20 \mathrm{mmol} / 1$ of Tris-buffered saline- $0.1 \%$ Tween-20 (TBST) buffer containing $5 \%$ skim-milk, kept at $4^{\circ} \mathrm{C}$ overnight, and probed with specific primary antibodies (Mouse monoclonal antibody against $\mathrm{Bcl}-2$ and $\mathrm{Bax}$ and mouse monoclonal antibody against $\beta$-actin, 1:1,000 dilution) overnight at $4^{\circ} \mathrm{C}$. After being washed with TBST for $1.5 \mathrm{~h}$, the membranes were incubated with horseradish peroxidase (HRP)-conjugated anti-mouse secondary antibody (1:1,000 dilution) for $1 \mathrm{~h}$ at room temperature and washed with TBST for $40 \mathrm{~min}$. Protein-antibodies immuno-reactive complexes were visualized using an enhanced chemiluminescene (ECL) Western blotting detection reagent according to the manufacturer's recommendations. The experiment was repeated three times.

\section{Statistical analysis}

All the experimental data were expressed by mean \pm SD and statistical analysis was performed using SPSS (version 17). Data represented are average of three independent experiments in each group. The comparison between two groups was done using Student's t-test while the comparison between multiple groups was performed using one-way analysis of variance. $\mathrm{P}$ value $<0.05$ was considered statistically significant.

\section{Results}

The inhibitory effect of $C 225$ on the proliferation of MDAMB-231 cells

The effect of $\mathrm{C} 225$ on the proliferation of MDAMB-231 cells was determined using CCK-8 assays. As shown in Figure 1, various concentrations of C225 inhibited the proliferation of MDA-MB-231 cells and a significant difference was found compared with control group $(\mathrm{P}<0.05)$. The inhibition rate became more obvious with the increase of concentration, which presented dose-dependence. The half inhibitory concentration $\left(\mathrm{IC}_{50}\right)$ was calculated according to the concentration and growth inhibition rate. The $\mathrm{IC}_{50}$ was equal to $(151 \pm 2.98) \mathrm{nmol} / 1$.

Asian Pacific Journal of Cancer Prevention, Vol $20 \mathbf{3 1 3}$ 


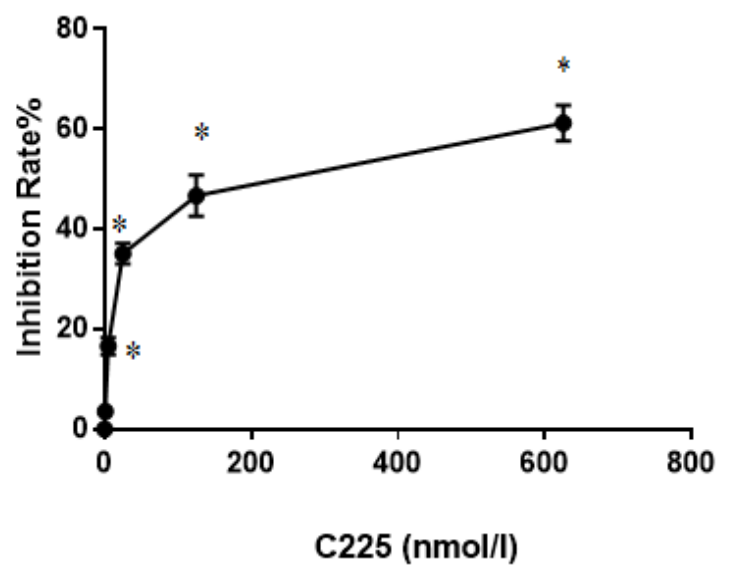

Figure 1. Effect of C225 on the Inhibition Rate of MDA-MB-231 Cells at Various Concentrations; Note, ${ }^{*}$ compared with control group $\mathrm{P}<0.05$

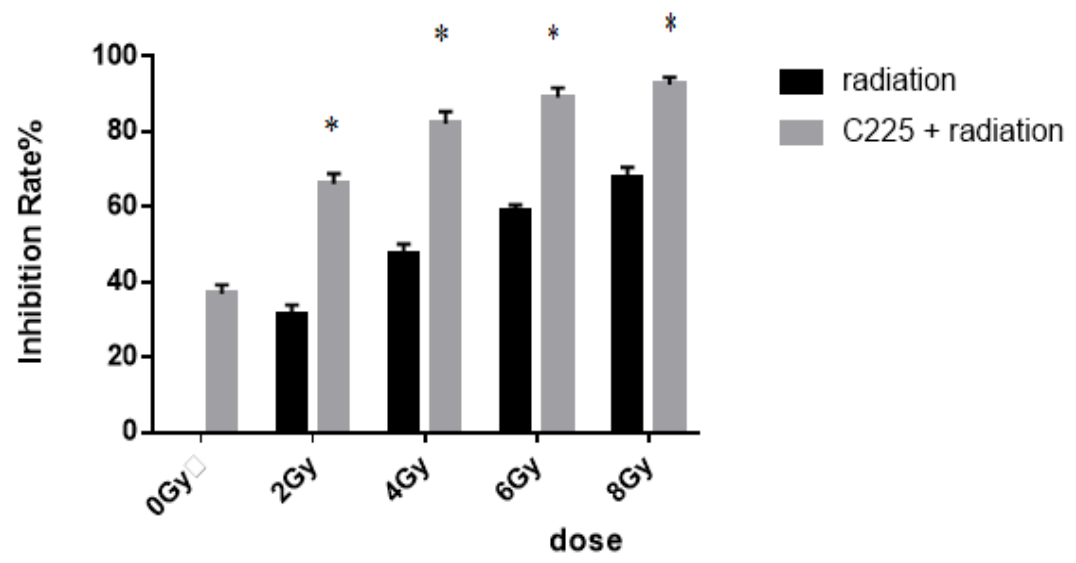

Figure 2. The Inhibition Effect of C225 Combined with Radiation on the Proliferation of MDA-MB-231 Cells; Note, $*$ compared with radiation group at the same dosage $\mathrm{P}<0.05$

Given that $1 / 5 \mathrm{IC}_{50}$ is a non-toxic concentration, $1 / 5 \mathrm{IC}_{50}$ is suitable for the experimental concentration of radiation. Therefore, we used the concentration of $30 \mathrm{nmol} / \mathrm{l}$ for the subsequent experiments.

The inhibitory effect of $C 225$ combined with radiation on the proliferation of $M D A-M B-231$ cells

Compared with the single radiation group $(2,4,6$, $8 \mathrm{~Gy}$ ), the proliferation inhibition was more obvious in C225 combined with the corresponding dose of radiation group, revealing a statistically significant difference. The $\mathrm{Q}$ values were $1.17,1.22,1.21$, and 1.16 at the dose of 2Gy, 4 Gy, 6 Gy, and 8 Gy; respectively, which were more than 1.15 (Figure 2). This indicated that there was certain synergistic effect between $\mathrm{C} 225$ and radiation.

\section{Clonogenic survival assay}

The clonogenic survival assay was used to determine the enhancement of radio-sensitivity by $\mathrm{C} 225$. The survival curve of radiation alone and C225 combined

Table 1. Radiation Biology Parameters Using Single-Hit Multi-Target Model

\begin{tabular}{lcccccc}
\hline Group & $\begin{array}{c}\mathrm{D} 0 \\
(\mathrm{~Gy})\end{array}$ & $\begin{array}{c}\mathrm{Dq} \\
(\mathrm{Gy})\end{array}$ & $\mathrm{SF}$ & SER $_{\mathrm{D} 0}$ & SER $_{\mathrm{Dq}}$ & SER $_{\mathrm{SF} 2}$ \\
\hline radiation & 2.76 & 1.92 & 0.65 & & & \\
C225+ radiation & 1.96 & 1.18 & 0.471 & 1.41 & 1.63 & 1.38 \\
\hline
\end{tabular}

with radiation are shown in Figure 3. The radio-biological parameters of each group are shown in Table 1.

Effects of C225 combined with radiation on the apoptosis of $M D A-M B-231$ cells

As shown in Figure 4, the apoptosis of MDA-MB231cells in C225 plus radiation group was significantly higher than that in radiation group at all expose doses, and the difference between the two groups was statistically significant $(\mathrm{P}<0.05)$.

Effect of C225 combined with radiation on the cell cycle of MDA-MB-231 cells

The results showed that the cells in $\mathrm{C} 225$ plus radiation group were mainly at G0/G1 and G2/M stage. Compared with the $\mathrm{C} 225$ group and the radiation group, the proportion of S phase cells decreased more significantly in $\mathrm{C} 225$ plus radiation group $(\mathrm{P}<0.05)$, which showed that $\mathrm{C} 225$ could induce obvious G0/G1 block (Figure 5). That is to say C225 could make MDA-MB-231 cells be arrested in $\mathrm{G} 0 / \mathrm{G} 1$ phase and slow down the cell cycle progression which was associated with the inhibition of proliferation.

Detecting the effect of $C 225$ combined with radiation on signaling protein expression of p-EGFR, $p$-Akt, and p-P38 using Western blot

The $\beta$-actin protein expression was used as an 


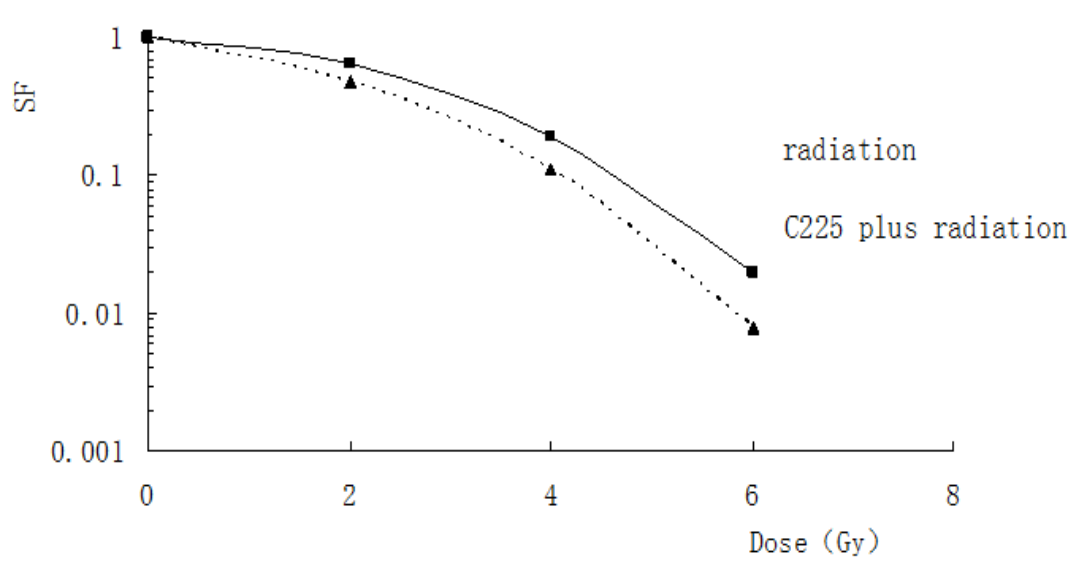

Figure 3. The Clonogenic Survival Assay of Combination of C225 (30 nmol/l) with Laddered Doses of Radiation (0, 2, 4, and 6 Gy) of 6 MV X-ray; Note, SF represents Survival Fraction; Solid line represents SF of radiation group; Dotted line represents SF of C225 plus radiation group.

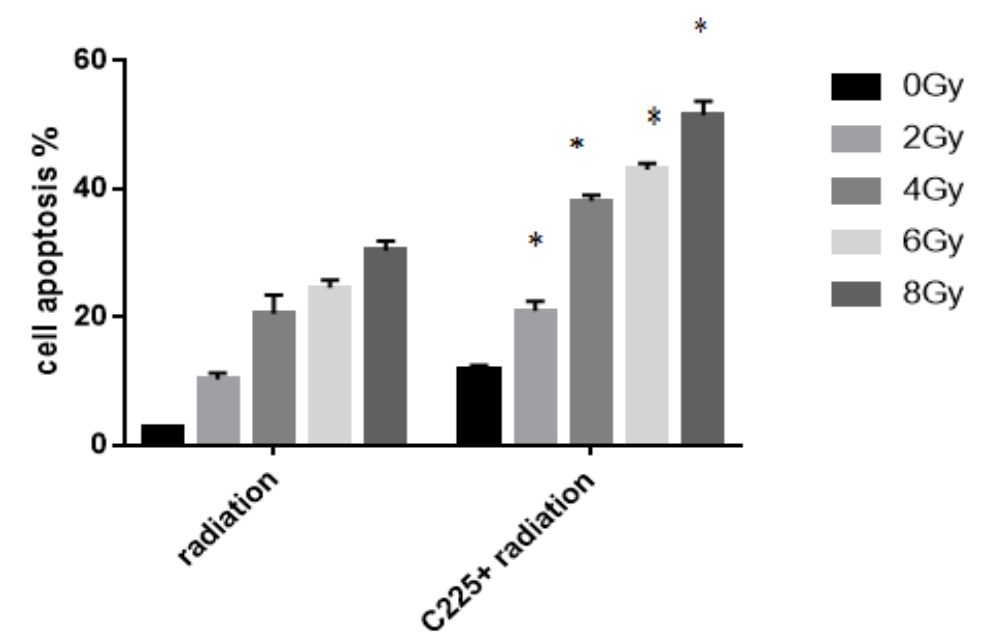

Figure 4. Effects of C225 Combined with Radiation on the Apoptosis of MDA-MB-231 Cells; Note, *compared with radiation group at the same dosage $\mathrm{P}<0.05$

internal reference. The ratio of the protein expression band intensity of the normal control group and that of the corresponding $\beta$-actin was considered as the reference value 1 . The results showed that the expressions of $\mathrm{p}-\mathrm{Akt}$, p-P38, and p-EGFR were significantly inhibited in C225 combined with radiation. Compared with the control group, the difference was statistically significant $(\mathrm{P}<0.05)$.
The signal protein expression in all groups and the protein relative expression intensity ratio are shown in Figure 6a and Figure 6b, respectively.

Detecting the expression of apoptosis related Caspase-3 using Western blot

The results showed that the expression of Caspase-3

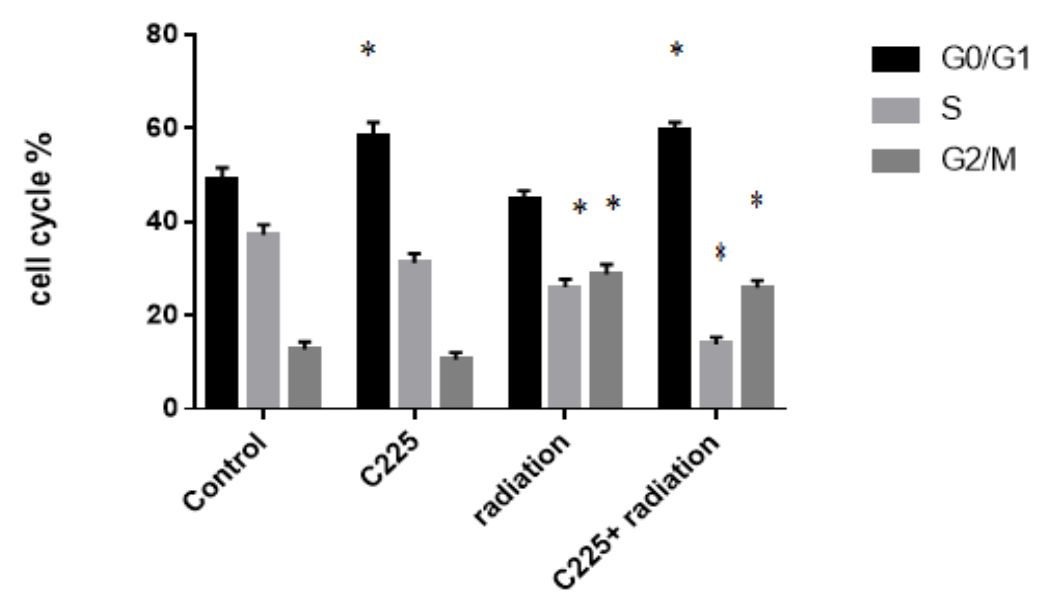

Figure 5. Effect of C225 Combined with Radiation on the Cell Cycle of MDA-MB-231 Cells; Note,* compared with control group $\mathrm{P}<0.05$ 
A $\quad$ B $\quad$ C $\quad$ D

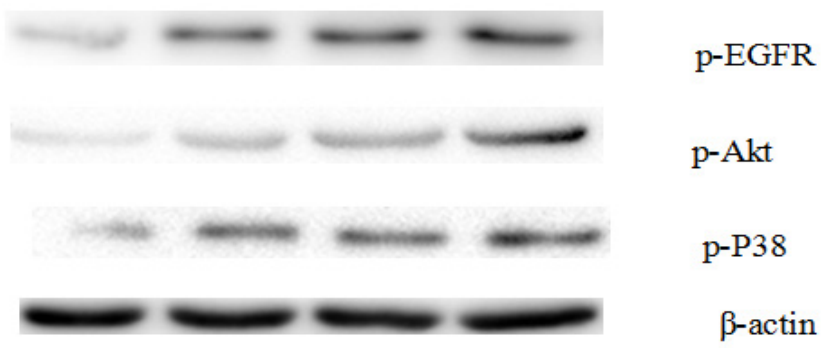

Figure 6a. Effect of C225 and/or Radiation on MDA-MB-231 Cell Signaling Protein Expression; A. C225 plus radiation group; B. radiation group; C. C225 group; D. Control group.
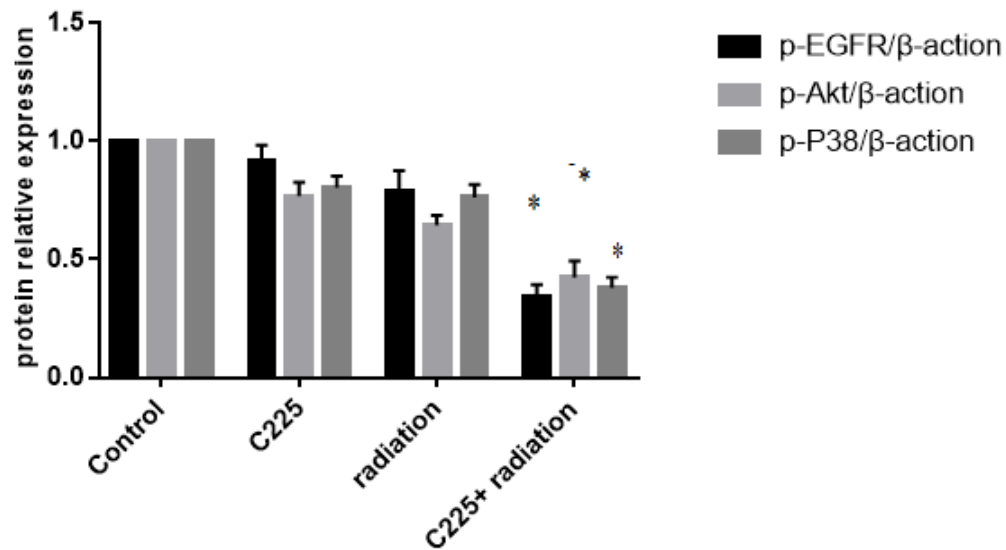

Figure 6b. The Signal Protein Relative Expression of C225 and/or Radiation; Note, *compared with control group $\mathrm{P}<0.05$

was significantly enhanced in C225 plus radiation group and the difference was statistically significant compared with the control group $(\mathrm{P}<0.05)$. The expression of Caspase- 3 in all groups and the relative expression of Caspase-3 intensity ratio are shown in Figure $7 \mathrm{a}$ and Figure $7 b$, respectively.

\section{Discussion}

Certain studies have shown that EGF can act not only as a growth factor to promote cell proliferation but also function as a survival factor to suppress apoptosis when cells are challenged with various death signals (Marciniak et a1., 2004). C225, as a kind of EGFR inhibitors, was shown to inhibit the growth of some EGFR-expressing cell lines. The mechanism of growth inhibition seemed to involve the inhibition of EGF-induced downstream signaling pathways. C225 in combination with EGFR not only blocked the secretion of TGF- and signal transduction but also decreased the expression of EGFR on the cell membrane surface (Liao and Carpenter, 2009). Clinically, C225 combined with radiotherapy showed a significant effect on head and neck squamous cell carcinoma and $\mathrm{C} 225$ combined with radiotherapy as a routine treatment on head and neck squamous cell carcinoma has been accepted by the majority of doctors (Sok et al., 2006; Pozzi et al., 2016; Suntharalingam et al., 2017 ; Weidhaas et al., 2017).

Increasing studies have shown that $\mathrm{C} 225$ could inhibit the proliferation of a variety of tumor cells, such as tongue cancer, colorectal cancer, and lung squamous cell carcinoma (Zhang et al., 2010; Tian et al., 2012; Wang et al., 2012). In the present study, we confirmed that C225 significantly inhibited MDA-MB-231 cell growth using CCK-8 and clonogenic assays. Our results on CCK-8 assay showed that the inhibition rate of MDA-MB-231

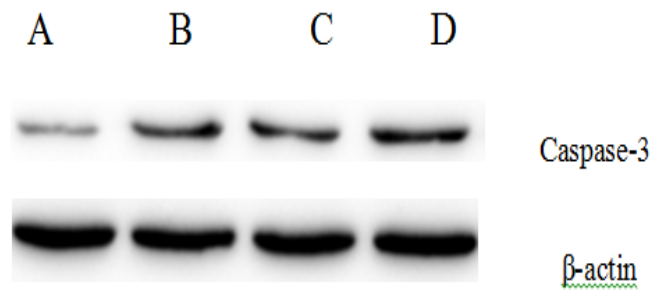
A. Control group
B. C225 group
C. radiation group
D. C225 plus radiation group

Figure 7a. Effect of C225 and/or Radiation on the Expression of Caspase-3 


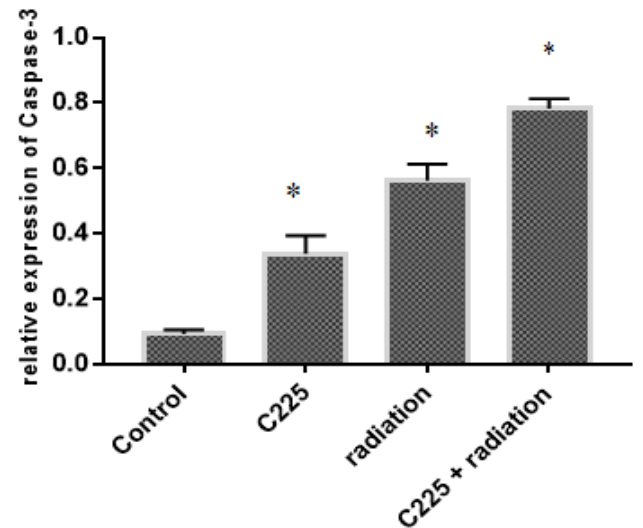

Figure 7b. The Relative Expression of Caspase-3 of C225 and/or Radiation; Note, *compared with control group $\mathrm{P}<0.05$

cells increased with the increase of $\mathrm{C} 225$ concentration, thus it can be concluded that the inhibition effect is dose-dependent (Figure 1). The proliferation inhibition rate of cells in C225 plus radiation group was significantly increased compared with that of the single radiation group at the corresponding expose dose. The $\mathrm{Q}$ values of each dose group were more than 1.15 , which showed that C225 enhanced the anti-proliferation effect of radiation. Importantly, C225 in combination with radiation produced significant synergistic inhibition of MDA-MB-231 cell growth which is consistent with findings of other studies, revealing that both $\mathrm{C} 225$ and radiation have synergistic growth inhibition on the tumor cells (Zhang et al., 2010; Tian et al., 2012; Wang et al., 2012).

For X-rays radiation, DNA is the main target to kill tumor cells, so single-hit multi-target model $\mathrm{SF}=1-\left(1-\mathrm{e}^{-\mathrm{D} / \mathrm{D} 0-}\right)^{\mathrm{N}}$ is widely used to measure cell radio-sensitivity in the field of radiobiology, which is currently the gold standard to evaluate whether certain drug has radio-sensitivity or not (Yao et al., 2014). Our results showed that radiation biology parameters $\left(\mathrm{D}_{0}, \mathrm{D}_{\mathrm{q}}\right.$, and $\mathrm{SF}_{2}$ ) in $\mathrm{C} 225$ plus radiation group were lower than those in radiation group (Table 1). In the present study, we confirmed that C225 could inhibit MDA-MB-231 cell growth using clonogenic assay. C225 in combination with radiation produced significant synergistic inhibition of MDA-MB-231 cell growth. The dose-survival curve of C225-treated MDA-MB-231 cells exhibited a narrow shoulder (indicating a decrease in $\mathrm{D}_{\mathrm{q}}$ ) and a greater slope rate (indicating a decrease in $\mathrm{D}_{0}$ ). Through analysis of cell survival curves, we found that the $\mathrm{D}_{\mathrm{q}}$ value of $\mathrm{C} 225$ combined with radiation is smaller and the curves had no apparent shoulder area, indicating that the C225 increased the sensitivity of the MDA-MB-231 cells to radiation. At the same time, the $\mathrm{D}_{0}$ value was relatively lower suggesting that the reasonable lower doses of radiation could also kill tumor cells when coupled with $\mathrm{C} 225$. The decreased $\mathrm{SF}_{2}$ value of the C225-treated MDA-MB-231 cells indicated the radio-sensitization effect of $\mathrm{C} 225$ on MDA-MB-231 cells. The sensitive enhancement ratio $\left(\mathrm{SERD}_{0}, \mathrm{SERD}_{\mathrm{q}}\right.$, and $\left.\mathrm{SERSF}_{2}\right)$ of $30 \mathrm{nmol} / 1 \mathrm{C} 225$ was $1.41,1.63$, and 1.38 , respectively, which suggested that C225 had radio-sensitization effect on MDA-MB-231 cells (Figure 3).
Cell cycle regulation is an important factor to determine the radiation sensitivity of tumor cells (Geldof et al., 2003). The tumor cells at different cell cycle have different radiation sensitivity. In general, G2/M phase is the most sensitive phase to radiation, followed by $\mathrm{G} 0$ / G1 phase, while $\mathrm{S}$ phase is the most resistant phase to radiation (Pawlik and Keyomarsi, 2004). In our study C225 combined with radiation induced significant G0/ G1 arrest, a sharp decrease in the fraction of cells in the $\mathrm{S}$ phase, and the accumulation of cells in the G2/M phase as revealed by FCM. Compared with the control group and the radiation group, the proportion of cells in G0/G1 phase was increased and the proportion of $S$ phase cells was significantly decreased (Figure 5), which indicated that the doubling time of the MDA-MB-231 cells was significantly prolonged, and the cells in the stationary phase were significantly increased. The mechanism of radiation sensitization of $\mathrm{C} 225$ on MDA-MB-231 cell could be the prevention of $\mathrm{G} 1$ phase conversion to $\mathrm{S}$ phase and slowing down the process of cell cycle, resulted in the growth rate decrease. In this study, the effect of C225 on the proliferation inhibition of MDA-MB-231 cells was confirmed by CCK8. There is a very close relationship between tumor cell cycle arrest and radiation sensitivity. Under normal condition, cell cycle arrests at some point in order to repair damage. When the damage repairs successfully, cell cycle continues, otherwise cells undergo apoptosis. Repairing the radiation-induced damage for the cells arrested at $\mathrm{G} 2 / \mathrm{M}$ phase needs the participation of many growth factors (Fan and Weiss, 2005). G0/G1 phase arrest was associated with the increased apoptosis of tumor cells, thereby increasing the sensitivity of tumor cells to radiation. Therefore, the degree of G0/G1 arrest was positively correlated with the cell radiation sensitivity. Recently C225 has been shown to cause cell cycle arrest in the $\mathrm{G} 0 / \mathrm{G} 1$ phase and reduce the $\mathrm{S}$ phase cells that are resistant to radiation, thereby increasing the radiation sensitivity of cells, which were consistent with our results (Zhang et al., 2010; Tian et al., 2012; Wang et al., 2012).

Studies have shown that activation of EGFR can inhibit apoptosis of tumor cells, reducing the radiation sensitivity (Peltola et al., 2009). Cellular apoptosis represents another process that may influence the ultimate response of a particular tumor to radiation. When radiation combined with $\mathrm{C} 225$, the apoptosis rate was higher than that of radiation group (Liccardi et al., 2011). Our results showed that $\mathrm{C} 225$ could promote the apoptosis of MDA-MB-231 cells compared to the cells in control group. The apoptosis rate of MDA-MB-231 cells in combined group was higher than that of radiation group at different doses $(\mathrm{P}<0.05)$, which was significantly higher than that of control group (Figure 4). Thus, inducing cell apoptosis may be one of the mechanisms of enhanced cellular radio-sensitivity by $\mathrm{C} 225$.

A series of biochemical reactions occur in the tumor cells, which can restore the structure and function of the tumor cells, even enhance the proliferation, inhibit the apoptosis, or make tumor cells more resist to radiation. In the above process, the signal transduction pathway of cells plays an important role. Previous research indicated that EGFR involved in cell proliferation was mainly 
self-autophosphorylation activated through the binding of the ligand and downstream signaling pathways were further activated, inhibiting cell apoptosis and promoting cell proliferation (Shi et al., 2012). The EGFR signal transduction pathway transfer activation signal mainly through the downstream Ras-Raf-MAPK pathway and PI3K/Akt pathway. The cascade reaction can be initiated after Ras activation in the Ras-Raf-MAPK pathway, which leads to the activation of MAPK. Phosphorylation of p38MAPK (p-P38) plays a critical role in the regulation of proliferation, apoptosis, and cell cycle (Platanias, 2003). Akt protein B (protein kinase $B, P K B$ ) is the core of PI3K/Akt signal transduction pathway, which is the most important target kinase in the downstream PI3K signal transduction pathway. Activated Akt can activate or inhibit many kinds of downstream target proteins through phosphorylation of a series of substrates, so as to induce cell proliferation and promote cell survival, tumor angiogenesis, and other biological behavior of malignant tumor cells (Liang and Slingerland, 2003; Song et al., 2005). At present, there are many studies on the mechanism of radiation sensitization of $\mathrm{C} 225$, which mainly considers the imbalance of the downstream signal transduction system to induce cell cycle arrest, apoptosis, and abnormal repair. Takaoka et al., (2012) confirmed that C225 could reduce the levels of phosphorylated EGFR and Akt in oral squamous cell carcinoma NA and Ca9-22 cells. However, the mechanism of radiation sensitization of EGFR and its downstream PI3K/Akt signaling pathway on the breast cancer cells, especially TNBC cells, has not been found yet. In this study, we evaluated EGFR signal transduction system, such as p-EGFR, p-P38 and p-AKT in MDA-MB-231 cells when C225 was combined with radiation, and the results showed that the expression of p-EGFR, p-P38 and p-AKT were significantly inhibited by C225 plus radiation (Figure 6a, Figure 6b). We speculated that Akt phosphorylation might be an early response to radiation injury, which might be an important cause of tumor cell radiation resistance. The expression of $\mathrm{p}$-Akt was lower in the combination group than that in radiation group. We found that $\mathrm{C} 225$ could inhibit the activation of PI3K/Akt signaling pathway, suggesting that C225 could enhance the sensitivity of TNBC cells to radiation by inhibiting EGFR signal transduction system. As we know, radiation can activate the EGFR/ras/raf/MAPK proliferative pathway through the release of TGF and the activation of the EGFR tyrosine kinase. EGFR activation may be a cell-survival response that blocks apoptotic signals in tumor cells undergoing cytotoxic damage. In our study, C255 increased MDA-MB-231 cell apoptosis after exposure to different doses of radiation. Importantly, C255 significantly inhibited the radiation-induced EGFR-MAPK signaling pathway activation in MDA-MB-231 cells as evidenced by the reduced the phosphorylation of p38-MAPK molecules by C225. Our research suggested that radiation-induced cell apoptosis increased when EGFR-MAPK signaling was inhibited.

Caspase, a family of proteases in mammalian cells, plays an important role in the process of cell apoptosis. Once caspase is activated, it will produce a cascade reaction, leading to apoptosis eventually. Caspase-3 is a key enzyme in the execution of cell apoptosis in the caspase family members, and it is also the common effect factor involved in the exogenous and endogenous signal transduction pathway of apoptosis (Hassan et al., 2012). Our results showed that, compared with the control group, the single $\mathrm{C} 225$ group, and the radiation group, the expression of Caspase- 3 in C225 plus radiation group was significantly enhanced, which showed that $\mathrm{C} 225$ combined with radiation enhanced the cytotoxic effect of radiation on MDA-MB-231 cells and promoted the apoptosis of MDA-MB-231 cells (Figure7a, Figure 7b).

In summary, $\mathrm{C} 225$ has a significant role in the radiation sensitization, and its mechanism may be related to the inhibition of EGFR signal transduction pathway and increased apoptosis. With the subsequent development of more related experiments, the mechanism of $\mathrm{C} 225$ radiation sensitization will be clear. This provides a rationale for combining $\mathrm{C} 225$ and radiotherapy in the treatment of TNBC. Radiotherapy combined with C225 might improve therapeutic effect and reduce the total radiation dose in a clinical setting, which is of potential clinical interest. C225 will be expected to become a promising radiation sensitization agent in the future.

\section{Conflict of interest}

The authors declare that they have no conflict of interest.

\section{References}

Dittmann K, Mayer C, Fehrenbacher B, et al (2005). Radiationinduced epidermal growth factor receptor nuclear import is linked to activation of DNA-dependent protein kinase. $J$ Biol Chem, 280, 31182-9.

Diaz Miqueli A, Rolff J, Lemm M, et al (2009). Radiosensitisation of U87MG brain tumours by anti-epidermal growth factor receptor monoclonal antibodies. Br J Cancer, 100, 950-8.

Fan QW, Weiss WA (2005). RNA interference against a glioma-derived allele of EGFR induces blockade at G2M. Oncogene, 24, 829-37.

Gupta AK, Bakanauskas VJ, Cerniglia GJ, et al (2001).The Ras radiation resistance pathway. Cancer Res, 61, 4278-82.

Geldof AA, Plaizier MA, Duivenvoorden I, et al(2003). Cell cycle perturbations and radiosensitization effects in a human prostate cancer cell line. J Cancer Res Clin Oncol, 129, $175-82$.

Hassan F, Meduru S, Taquchi K, et al (2012). Carvedilol enhances mesenchymal stem cell therapy for myocardial infarction via inhibition of caspase-3 expression. J Pharmacol Exp Ther, $343,62-71$.

Italiano A, Vandenbos BF, Otto J, et al (2006). Comparison of the epidermal growth factor receptor gene and protein in primary non-small-cell lung cancer and metastatic sites: Implications for treatment with EGFR-inhibitors. Ann Oncol, 7, 981-5.

Jemal A, Bray F, Center MM, et al (2011). Global cancer statistics. CA Cancer J Clin, 61, 69-90.

Krause M, Prager J, Zhou X, et al (2007). EGFR-TK inhibition before radiotherapy reduces tumour volume but does not improve local control: Differential response of cancer stem cells and nontumourigenic cells?. Radiother Oncol, 83, 316-25.

Kaya V, Yildirim M, Yazici G, et al (2018). Effectiveness of platinum-based treatment for triple negative metastatic breast cancer: a meta-analysis. Asian Pac J Cancer Prev, 
19, 1169-73.

Liang J, Slingerland JM (2003). Multiple roles of the PI3K/ PKB(Akt) pathway in cell cycle progression. Cell Cycle, 2, 339-45.

Liu YQ, Poon RT, Shao W, et al (2007). Blockage of epidermal growth factor receptor by quinazoline tyrosine kinase inhibitors suppresses growth of human hepatocellular carcinoma. Cancer Lett, 248, 32-40.

Liao HJ, Carpenter G (2009). Cetuximab/C225-induced intracellular trafficking of epidermal growth factor receptor. Cancer Res, 69, 6179-83.

Liccardi G, Hartley JA, Hochhauser D (2011). EGFR nuclear translocation modulates DNA Repair following cisplatin and ionizing radiation treatment. Cancer Res, 71 ,1103-14.

Liang ZG, Lin GX, Ye JX, et al (2018). Cetuximab or nimotuzumab versus cisplatin concurrent with radiotherapy for local-regionally advanced nasopharyngeal carcinoma: a meta-analysis. Asian Pac J Cancer Prev, 19, 1397-404.

Marciniak DJ, Rishi AK, Sarkar FH, Majumdar APN (2004). Epidermal growth factor receptor-related peptide inhibits growth of PC-3 prostate cancer cells. Mol Cancer Ther, $\mathbf{3}$, 1615-21.

Mouh FZ, Mzibri ME, Slaoui M, Amrani M (2016). Recent progress in triple negative breast cancer research. Asian Pac J Cancer Prev, 17, 1595-608.

Oostra DR, Macrae ER (2014). Role of trastuzumab emtansine in the treatment of HER2-positive breast cancer. Breast Cancer (Dove Med Press), 6, 103-13.

Pawlik TM, Keyomarsi K (2004). Role of cell cycle in mediating sensitivity to radiotherapy. Int J Radiat Oncol Biol Phys, 59, 928-42.

Platanias LC (2003). The p38 mitogen-activated protein kinase pathway and its role in interferon signaling. Pharmacol Ther, 98, 129-42.

Peltola K, Hollmen M, Maula SM, et al (2009). Pim-1 kinase expression predicts radiation response in squamocellular carcinoma of head and neck and is under the control of epidermal growth factor receptor. Neoplasia, 11, 629-36.

Pozzi C, Cuomo A, Spadoni I, et al (2016). The EGFR-specific antibody cetuximab combined with chemotherapy triggers immunogenic cell death. Nat Med, 22, 624-31.

Rades D, Wolff C, Nadrowitz R, et al (2009). Radioactive EGFR Antibody cetuximab in multimodal cancer treatment: Stability and synergistic effects with radiotherapy. Int $J$ Radiat Oncol Biol Phys, 75, 1226-31.

Song G, Ou yang GL, Bao S (2005). The activation of Akt/ PKB signaling pathway and cell survival. J Cell Mol Med, 9, 59-71.

Sok JC, Coppelli FM, Thomas SM, et al (2006). Mutant epidermal growth factor receptor (EGFRvIII) contributes to head and neck cancer growth and resistance to EGFR targeting. Clin Cancer Res, 12, 5064-73.

Shi Y, Tao Y, Jiang Y, et al (2012). Nuclear epidermal growth factor receptor interacts with transcriptional intermediary factor 2 to activate cyclin D1 gene expression triggered by the oncoprotein latent membrane protein1. Carcinogenesis, 33 1468-78.

Suntharalingam M, Winter K, Ilson D, et al (2017). Effect of the addition of cetuximab to paclitaxel, cisplatin, and radiation therapy for patients with esophageal cancer: The NRG oncology RTOG 0436 phase 3 randomized clinical trial. JAMA Oncol, 3, 1520-8.

Takaoka S, Iwase M, Uchida M, et al (2007). Effect of combining epidermal growth factor receptors and cisplatin on proliferation and apoptosis of oral squmaous cell carcinoma cells. Int J Oncol, 30, 1469-76.

Tian SQ, Wang JJ, Zhao Y, et al (2012). Radiosensitization of cetuximab on human tongue cancer cell line Tca8113. Chin J Radiol Med Prot, 32, 354-7.

Takada S, Sagawa T, Fujikawa K, et al (2018). Skin disorders and primary tumor location as prognostic factors in patients with metastatic colorectal cancer treated with cetuximab and chemotherapy. Asian Pac J Cancer Prev, 19, 2325-30.

Wang H, Wang JJ, Qu A, Liu JJ, Li JN (2012). Inhibitory effect of combination of cetuximab and irradiation on colorectal carcinoma CL187 cells. Chin J Radiol Med Prot, 32, 481-4.

Williams C, Lin CY (2013). Oestrogen receptors in breast cancer: Basic mechanisms and clinical implications. E Cancer Med Sci, 7, 370 .

Weidhaas JB, Harris J, Schaue D, et al (2017). The KRAS-variant and cetuximab response in head and neck squamous cell cancer: A secondary analysis of a randomized clinical trial. JAMA Oncol, 3, 483-91.

Yao JX, Yao ZF, Li ZF, Liu YB (2014). Radio-sensitization by Piper longumine of human breast adenoma MDA-MB-231 cells in vitro. Asian Pac J Cancer Prev, 15, 3211-7.

Zhou Y, Li S, Hu YP, et al (2006). Blockade of EGFR and ErbB2 by the novel dual EGFR and ErbB2 tyrosine kinase inhibitor GW572016 sensitizes human colon carcinoma GEO cells to apoptosis. Cancer Res, 66, 404-11.

Zhang YD, Wang JJ, Liu F, et al (2010). EGFR inhibitor C225 increases the radiosensitivity of human lung squamous cancer cells. Cancer Cell Int, 10, 1-7.

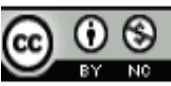

This work is licensed under a Creative Commons AttributionNon Commercial 4.0 International License. 